\title{
Synthesis of [2] Rotaxanes Derived from Host-Guest Interaction
}

\author{
Hemat Mohamed Dardeer ${ }^{1}$, Mamdouh Adly Hassan ${ }^{1}$ \\ ${ }^{1}$ Chemistry Department, Faculty of Science, South Valley University, Qena, 83523, Egypt \\ Correspondence: Hemat Mohamed Dardeer, Chemistry Department, Faculty of Science, South Valley University, \\ Qena, 83523,Egypt.E-mail: prof_hemat@yahoo.com
}

Received: December 19, $2014 \quad$ Accepted: January 15, $2015 \quad$ Online Published: April 26, 2015
$\begin{aligned} & \text { doi:10.5539/ijc.v7n1p161 } \\ & \text { URL: http://dx.doi.org/10.5539/ijc.v7n1p161 }\end{aligned}$

\begin{abstract}
Interlocked molecules such as rotaxanes and catenanes have a lot of studies in last twenty years. Due to their unique structures and properties. In this work [2] rotaxanes (A), (B), and (C) containing of $\alpha, \beta$ and/or $\gamma$ cyclodextrins have been prepared respectively. Construction of these compounds depend on forming stable inclusion complexes between cyclodextrin and hexamethylenediamine which ended with a bulky group 9,10-dihydro-9,10-ethanoanthracene-11,12-dicarboxylic anhydride. The chemical structure of synthesized inclusion complexes can be confirmed by spectral analysis and physical properties.
\end{abstract}

Keywords: rotaxanes, peseudorotaxanes, anhydride, host-gust interaction, cyclodextrins, inclusion complexes.

\section{Introduction}

Rotaxanes are compounds that consist of a linear species and cyclic species, linked together in a threaded architecture by non-covalent interaction. There are two types of these compounds which are rotaxanes and pseudorotaxanes (Gibson et al., 1994, 1996) pseudorotaxanes means half rotaxanes are showed in Figure 1

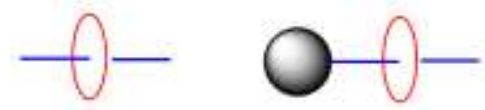

a. Pseudorotaxanes

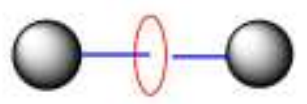

b. Rotaxane

Figure 1. Pseudorotaxane and Rotaxanes (Wenz, 1994)

The black balls here represent stoppers. They are bulky groups and can prevent the dethreading of the cyclic component. Rotaxanes are one example of mechanically interlocked molecules (Frisch et al., 1961; Walba, 1985; Breault et al., 1999), such as catenanes, and knots (Sauvage et al., 1999) which discovered from 30 years ago. Recently, these compounds have steadily attention. Rotaxanes can be covalently linked together in many ways to create polymeric species called polyrotaxanes. The chemical structure of CDs consists of lipophilic inner cavity and a hydrophilic external surface. The chair conformation of the glucopyranose units is the reason of creating this structure. CDs are almost as formed as a truncated cone instead of perfect cylinders. The structure of CDs has got also two types of hydroxyl groups, the first primary which placed in narrow edge of the cone. The second type of hydroxyl groups are secondary that located at wider edge of the cone. At present time rotaxanes and pseudorotaxanes (Steinbrunn et al., 1996) that include $\alpha$-CD which have long hydrophobic fragments was prepared (Manka et al.,1990; Isnin, et al., 1991, 1993). Pseudorotaxanes and rotaxanes driven by hydrophilic-hydrophobic forces are also published (Murakamiet al., 1997). Essentially there are three different patterns for the rotaxanes formation. The first route is clipping in that technique macrocycle segments cut into two parts then the macrocyclic molecule insert into (thread/axle), the second route is threading this way start with encircle macrocycle then bulky group (stopper) were attached to the end of thread. The third method is slippage in this method the selectivity of macrocyclc size is highly important, as the identical size or at least fit size of macrocycle permit to slip over bulky group through the thread at high temperatures. 


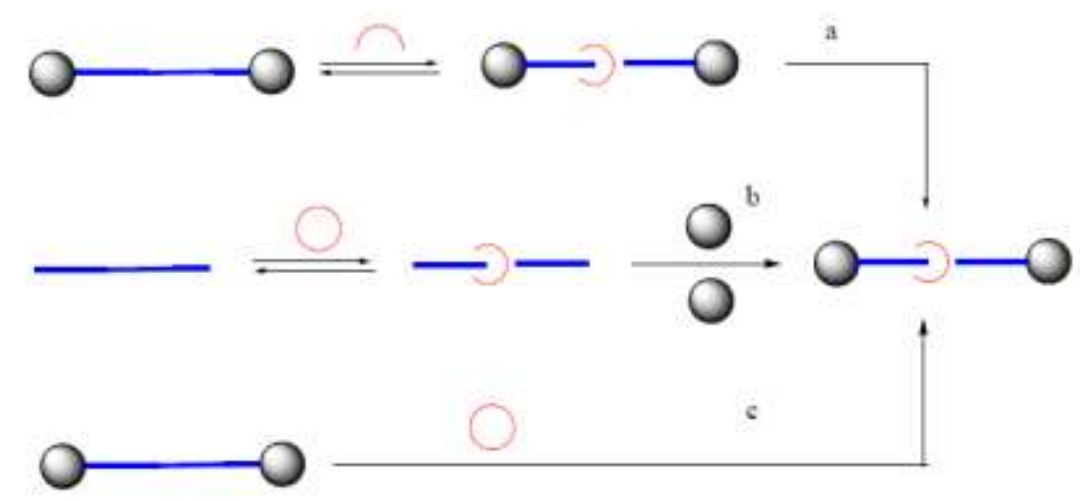

Figure 2. Three different approaches to the construction of rotaxanes (a) clipping, (b) threading, (c) slippage.

The forces that affect the threading, pseudorotaxanes and rotaxanes can be classified to seven types: Statistical threading, chemical conversion, hydrogen bonding, hydrophilic-hydrophobic interaction, metal-ligand complexation, $\pi-\pi$ stacking and charge transfer. Generally, the threading of a linear component through the macrocycle is formed thermodynamically by noncovalent bonding interactions to produce the most stable species in solution. While rotaxanes include no covalent bond between axes and rings are considered stable unit, due to highly free activation energy, which allow to be overcome over withdraw a ring from the axis of a rotaxane. CDs played important role in formation of rotaxane compounds due to two reasons, first is the ability of CDs in shielding of the guest, since guest molecule within a CD cavity shows distinct unreactive nonpolar environment. This result is found in rotaxanes than other inclusion compounds, as the CD environment stays always around the guest. Complexation of molecules to cyclodextrins occurs through a non-covalent interaction between the molecule and the CD cavity. This is a dynamic process whereby the guest molecule continuously associates and dissociates from the host CD. Cyclodextrins (Dardeer, 2014) are insoluble in most organic solvents they are soluble in some polar, aprotic solvents. Although the solubility of cyclodextrins is higher in some organic solvents than in water. Complexation may not take place simply in non-aqueous solvents because of the increased affinity of the guest for the solvent compared to its affinity for water. Rotaxanes have a lot of applications in various fields. As light-harvesting antennae in the design of photosynthetic models (Schuster et al., 2006; Wange, 2009; Gallina et al., 2012), as catalysis (Thordarson, 2003), as anion sensing (Evans et al., 2011; Brown et al.,2012), as peptide delivery (Wang et al., 2007), as optical imaging agents (Baumes et al., 2010) and in manufacture artificial molecular machines (Balzani et al., 2000; Kinbara et al., 2006; Browne et al., 2006; Kay et al., 2007).

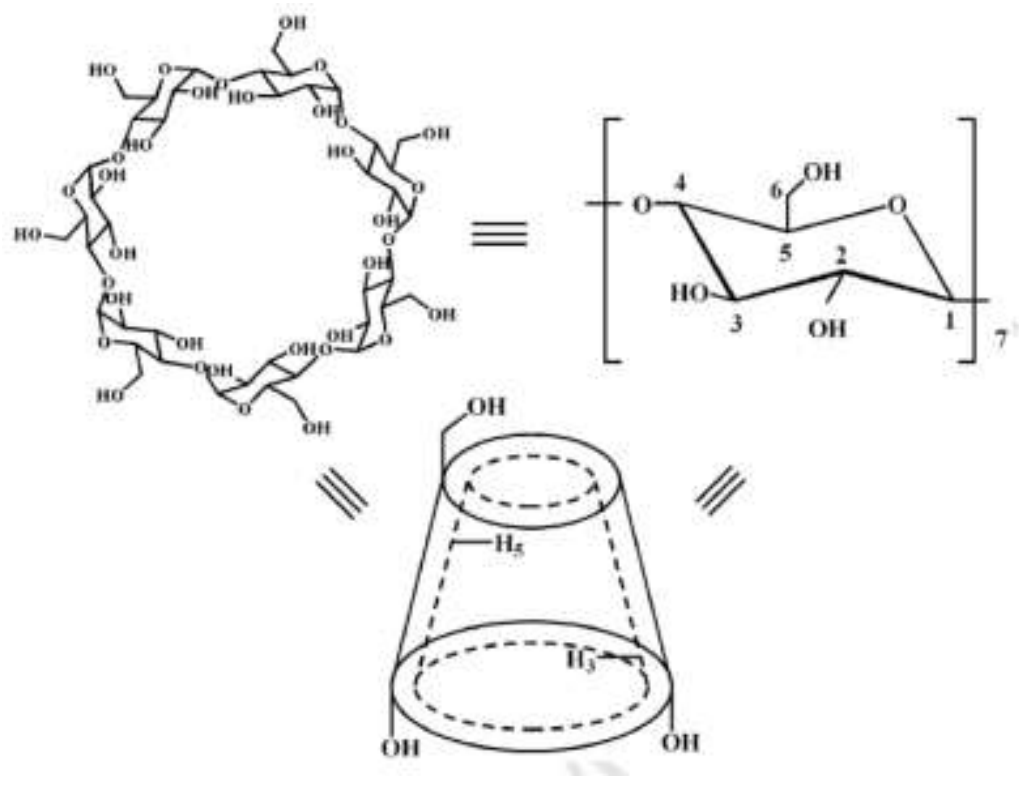

Figure 3. Show hydrogen protons of one glycopyranose unite in $\beta \mathrm{CD}$ (Xia Ge et al) 
Therefore, the aim of this search was to construct new rotaxanes compounds, confirmation of the chemical structures of these compounds by their spectral data and will make some studies and applications at the future on these inclusion complexes.

\section{Experimental}

\section{Instrumentations}

All melting points are uncorrected. The FT-IR spectra $(\mathrm{KBr})$ were recorded on a Shimadzu 408 spectrometer and carried out at the Central laboratory of South Valley University. ${ }^{1} \mathrm{H}-\mathrm{NMR}$ spectra were recorded using $300 \mathrm{MHz}$ Varian EM 390 spectrometer; chemical shifts are reported in ppm with TMS as an internal standard and are given in d units. Fast atom bombardment mass spectra, were determined using solvent NBA, carried out at Admin, IfOK, Rostock, Germany. Elemental analysis was carried out at the Microanalysis Unit at Cairo University.

\section{Synthesis}

Synthesis of [2] Rotaxane (A)

$\alpha$-Cyclodextrin (4 gm, $4.11 \mathrm{mmol})$ dissolved in DMSO (20 ml), hexamethylenediamine (0.21 gm, $1.81 \mathrm{mmole})$ was added with stirring for $1 \mathrm{hr}$. Then add the bulky group 9,10-dihydro-9,10-ethanoanthracene-11,12-dicarboxylic anhydride ( $0.5 \mathrm{gm}, 1.81 \mathrm{mmole})$ with continuously stirring for $1 \mathrm{hr}$. The reaction mixture poured onto ice/ water, the solid formed filtered off, wash with hot water to overcome the excess of $\mathrm{CD}$ and dried to give compound (A) ( $2.4 \mathrm{gm}, 1.5 \mathrm{mmole}$ ) as white crystals and obtained in $83 \%$ yield; m.p. over $320^{\circ} \mathrm{C}$; FT-IR $\left(\mathrm{KBr}, \mathrm{cm}^{-1}\right)$ : showed the presence of bands due to $(\mathrm{vOH}$ 's) at $3370 \mathrm{~cm}^{-1},\left(\mathrm{vC}=\mathrm{O}\right.$ 's) in the region $1730,1690 \mathrm{~cm}^{-1}$ and $(\mathrm{vC}-\mathrm{O}-\mathrm{C})$ glucosydic at $1159 \mathrm{~cm}^{-1} ; 1 \mathrm{H}-\mathrm{NMR}$ (300 MHz/DMSO) indicated at $\delta 2.6\left(\mathrm{~m}, 8 \mathrm{H}, 4 \mathrm{CH}_{2}\right) ; 2.9\left(\mathrm{t}, 4 \mathrm{H}, 2 \mathrm{CH}_{2}-\mathrm{N}\right) ; 3.4(\mathrm{t}, 6 \mathrm{H}, \mathrm{H} 4) ; 3.42(\mathrm{~d}, 4 \mathrm{H}, 4 \mathrm{CH} \mathrm{sp} 3)$; 3.5 (dd, 6H, H2); ); 3.64 ( dd,12H, H6); 3.68 (ddd, 6H, H5); 3.8 (t, 6H, H3); ); 4.4 (broad s-OH,6H, 6OHprimary hydroxyl); 4.7 (d, 4H, 4CH sp3); 4.84 (d, 6H, H1); 5.75 (broad s - $\mathrm{OH}, 12 \mathrm{H}, \mathrm{OH}$ secondary); 7.11-7.63 (m, 16H, arom. H); EA (\%C, \%H, \%N); Calc.: 58.35, 5.99, 1.75; Found, 58.38, 5.95, 1.72.

Synthesis of [2] Rotaxane (B)

To a suspension of $\beta$-Cyclodextrin (4 gm, $3.52 \mathrm{mmol})$ in DMSO $(20 \mathrm{ml})$, hexamethylenediamine $(0.21 \mathrm{gm}, 1.81$ mmole) was added with stirring for $1 \mathrm{hr}$. Then add the stoppered group 9,10-dihydro-9,10-ethanoanthracene-11,12- dicarboxylic anhydride ( $0.5 \mathrm{gm}, 1.81 \mathrm{mmole})$ with continuously stirring for $1 \mathrm{hr}$. The reaction mixture poured onto ice/ water, the solid formed filtered off, wash with hot water to overcome the excess of CD and dried to give compound (B) ( $2.7 \mathrm{gm}, 2.37$ mmole) as pale white crystals and obtained in $84 \%$ yield; m.p. over $330^{\circ} \mathrm{C}$; FT-IR $\left(\mathrm{KBr}, \mathrm{cm}^{-1}\right)$ : showed the presence of bands due to (vOH's) at $3375 \mathrm{~cm}-1, \quad(\mathrm{vC}=\mathrm{O}$ 's $)$ in the region $1750,1690 \mathrm{~cm}^{-1}$ and $(\mathrm{vC}-\mathrm{O}-\mathrm{C})$ glucosydic stretching vibrations at 1160 ; 1H-NMR (300 MHz/DMSO) indicated at $\delta 2.6\left(\mathrm{~m}, 8 \mathrm{H}, 4 \mathrm{CH}_{2}\right) ; 2.9\left(\mathrm{t}, 4 \mathrm{H}, 2 \mathrm{CH}_{2}-\mathrm{N}\right) ; 3.24(\mathrm{t}, 7 \mathrm{H}, \mathrm{H} 4) ; 3.38$ ( dd,7H, H2); 3.41 (d, 4H, 4CH sp3); 3.44 ( dd,14H, H6); 3.58 (ddd,7H, H5); 3.77 (t, 7H, H3); 4.41 (broad s, $7 \mathrm{H}, 7 \mathrm{OH}$ - primary hydroxyl); 4.77 (d, 4H, 4CH sp3); $4.82(\mathrm{~d}, 7 \mathrm{H}, \mathrm{H} 1) ; 5.7$ (broad s, 14H, OH secondary); 7.12-7.65 (m, 16H, arom. H); EA (\%C, \%H, \%N); Calc.: 57.04, 6.05, 1.58; Found, 57.11, 6.20, 1.55.

Synthesis of [2] Rotaxane (C)

$\gamma$-Cyclodextrin $(4 \mathrm{gm}, 3.08 \mathrm{mmol})$ was dissolved in DMSO $(20 \mathrm{ml})$, hexamethylenediamine $(0.21 \mathrm{gm}, 1.81$ mmole) was added with stirring for $1 \mathrm{hr}$. After that the bulky group 9,10-dihydro-9,10-ethanoanthracene-11,12dicarboxylic anhydride ( $0.5 \mathrm{gm}, 1.81 \mathrm{mmole})$ was added with continuously stirring for other $1 \mathrm{hr}$. The reaction mixture poured onto ice/ water, the solid formed filtered off, wash with hot water and dried to give rotaxane (C) $\left(2.9 \mathrm{gm}, 1,5\right.$ mmole) as buff precipitate and obtained in $83 \%$ yield; m.p. over $340^{\circ} \mathrm{C}$; FT-IR $\left(\mathrm{KBr}, \mathrm{cm}^{-1}\right)$ : showed the presence of bands due to (vOH's) at $3380 \mathrm{~cm}^{-1}$, ( $\left.\mathrm{vC}-\mathrm{O}-\mathrm{C}\right)$ glucosydic stretching vibrations at 1165 and $\left((\mathrm{vC}=\mathrm{O}\right.$ 's $)$ in the region $1760,1650 \mathrm{~cm}^{-1}$; $1 \mathrm{H}-\mathrm{NMR}(300 \mathrm{MHz} / \mathrm{DMSO})$ indicated at $\delta 2.61\left(\mathrm{~m}, 8 \mathrm{H}, 4 \mathrm{CH}_{2}\right)$; 2.88 (t, 4H, 2CH $2-\mathrm{N}) ; 3.41$ (d, 4H, 4CH sp3); 3.48(t, 8H, H4); 3.58 (dd, 8H, H2); ); 3.74 (dd, 16H, H6); 3.79 ( ddd, 8H, H5); 3.85 (t, 8H, H3); ); 4.63 (broad s, 8H, 8OH- primary alcohol); 4.75 (d, 4H, 4CH sp3); 5.52 ( d, 8H, H1); 5.78 (broad s, 16H, OH secondary);7.22-7.72 (m, 16H, arom. H); Fast atom bombardment showed M/S (m/z): $1930 \mathrm{M}+$; EA (\%C, \%H, \%N); Calc.: 55.95, 6.01, 1.45; Found, 55.92, 6.12, 1.43.

\section{Results and Discussion}

Synthesis of rotaxanes requires an axis to enter through a cyclodextrins ring, this called axial or thread also needs bulky groups to prevent dethreading of macrocyclic ring. The CDs arrangement in an inclusion compounds mostly depend on the polarity model of the guest. Thus, guest molecules can be classified into three main groups. 
Channel inclusion compounds of no polar guests, Inclusion compounds of amphiphilic guests and axial inclusion compounds of bola-amphiphiles. In this present work new [2] rotaxanes (A), (B) and (C) will be constructed.Via the threading route according to the following mechanism. Firstly, hexamethylenediamine (axis) will insert into cavity of $\alpha, \beta$, and $\gamma$ - cyclodextrins host molecule respectively, then addition of bulky molecules (9,10-dihydro-9,10-ethanoanthracene-11,12-dicarboxylic anhydride) that make as stopper in the end of axis to give inclusion complexes $\mathrm{A}, \mathrm{B}$, and $\mathrm{C}$ respectively (scheme 1). To obtain high yield of these compounds there are several requirements must be followed. The axis molecule must have efficiently to form a stable axial inclusion compound with the cyclodextrins, the axis should be long enough to outreach the CD cavity in order to allow the connection of stoppers, the inclusion compound of the axis must be soluble and the solvent used should not cause dissociation because the inclusion complex is mainly formed by hydrophobic-hydrophilic interaction. So that dimethyl sulfoxide and dimethyl formamide are suitable solvent for this reaction. In addition stopper and formed rotaxane should be soluble in these solvent to permit homogeneous reaction conditions. The stopper should be large enough to prevent dethreading. The elemental analysis can be confirmed the complex stoichiometry [1:1].The chemical structure of the synthesized rotaxanes were elucidated by spectral analysis. IR spectra showed bands in the region $3370-3380 \mathrm{~cm}^{-1}$ for O-H stretching vibration, sharp bands at 2900 , $2850 \mathrm{~cm}^{-1}$ for $\mathrm{CH}_{2}$ - aliphatic and the sharpening of the FT-IR bands at the region 1760-1650 for $\mathrm{C}=\mathrm{O}$ stretching vibration of amide. Also, appearing of characteristic bands for $\mathrm{C}-\mathrm{C}$ and $\mathrm{C}-\mathrm{O}$ stretching vibration at 1085, 1030 $\mathrm{cm}^{-1}$ respectively. ${ }^{1} \mathrm{H}-\mathrm{NMR}$ spectra illustrated $\mathrm{H}-3$ and $\mathrm{H}-5$ protons were situated inside the cavity, $\mathrm{H}-3$ closer to the wider rim and H-5 on the opposite. So that the chemical shift of H-5 appears upfield than H-3 due to the effect of aromatic rings and carbonyl groups. Also, the chemical shift of $\mathrm{H}-1$ appears downfield owning to the deshielding effect of the anthracene rings and oxygen atom of glycoside bond. Fast bombardment atom mass (FAB-mass) revealed the molecular mass of compound (C) M/S (m/z): 1930 and confirmed formation of this inclusion complex with [1:1] ratio figure 6 .

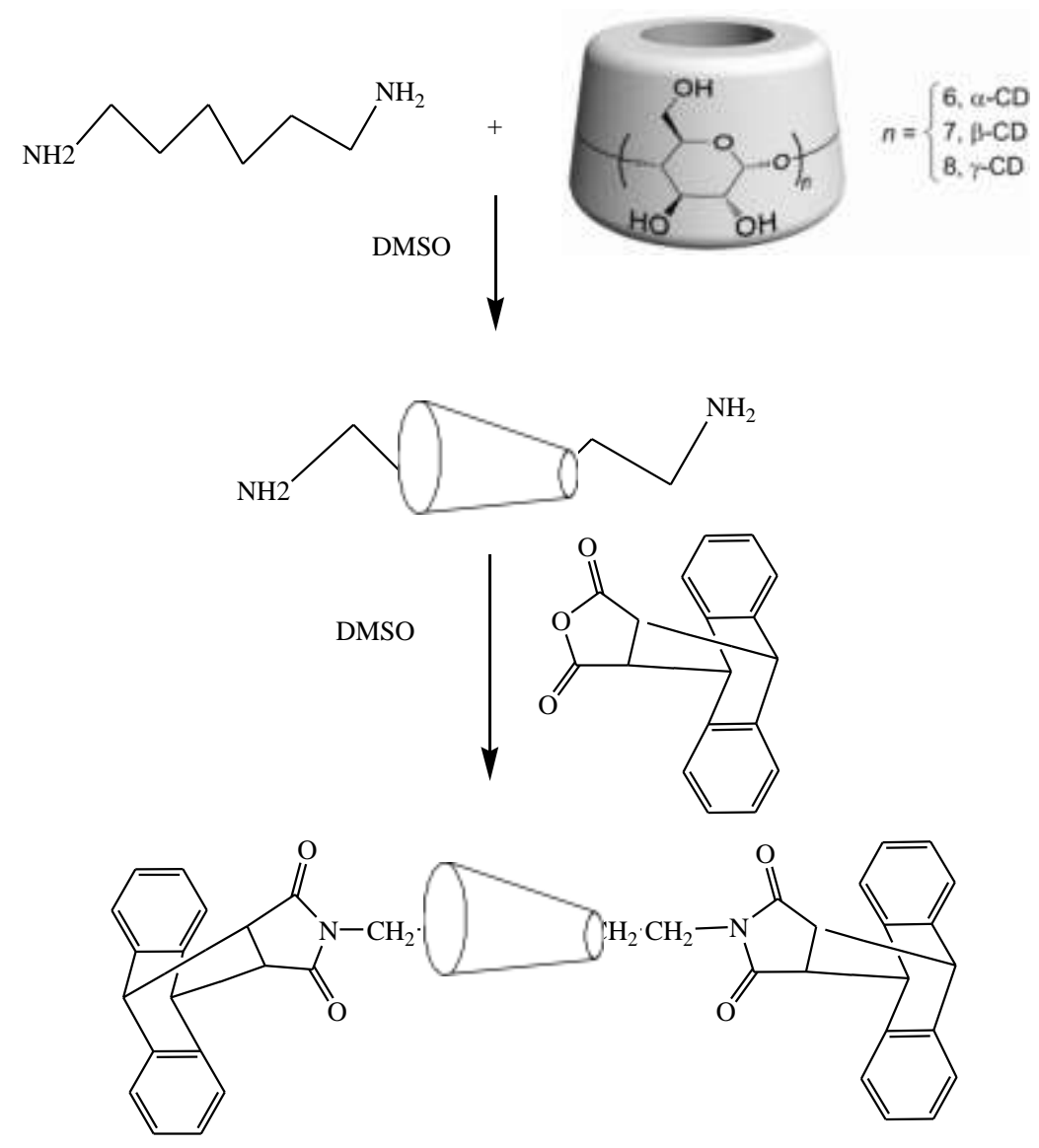

Scheme 1: Synthesis of [2]Rotaxanes (A), (B) and (C) 


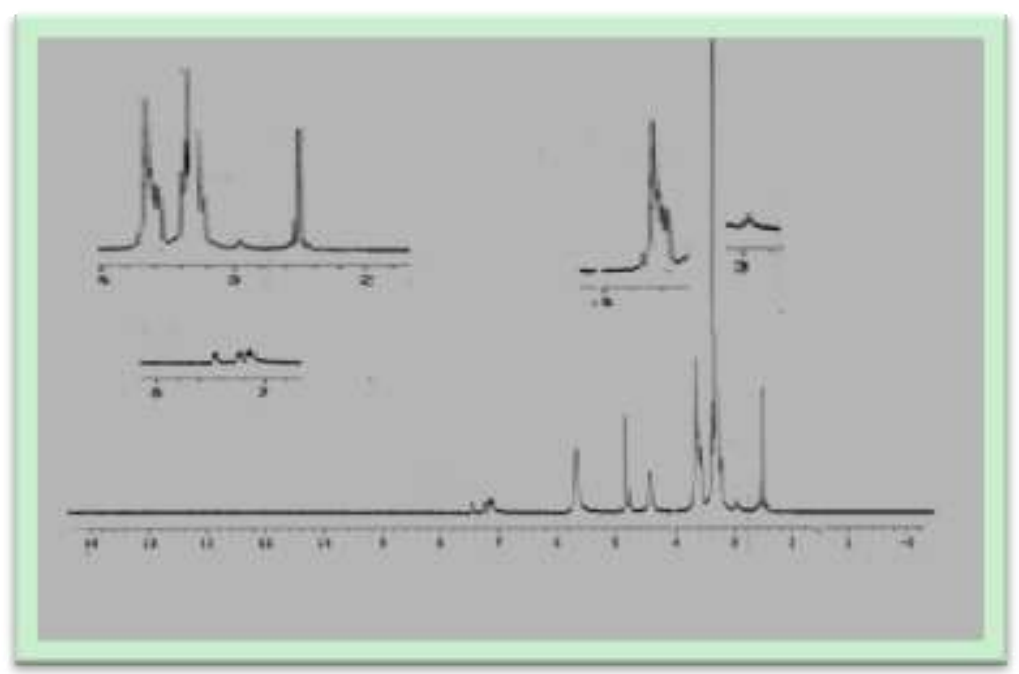

Figure $4 .{ }^{1} \mathrm{H}-\mathrm{NMR}$ spectra $\left(300 \mathrm{MHz}, 25^{\circ} \mathrm{C}\right.$, in DMSO) for compounds (B)

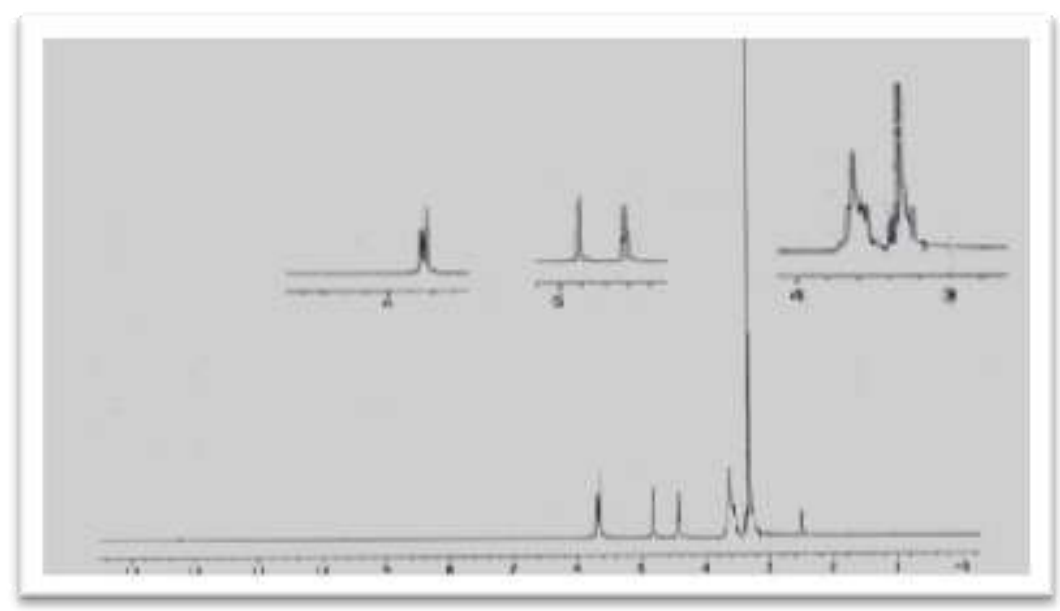

Figure 5. ${ }^{1} \mathrm{H}-\mathrm{NMR}$ spectra (300 MHz, in DMSO) for compounds $\beta$-CD

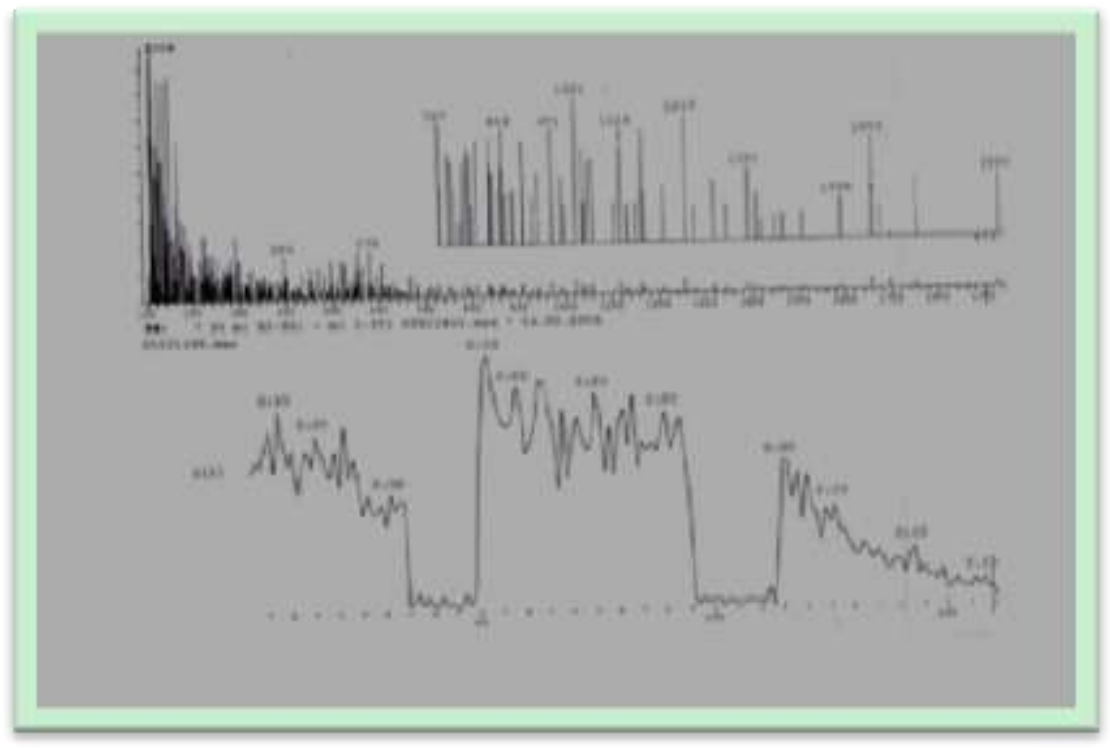

Figure 6. Fast Atom Bombardment Mass of compound (C) 


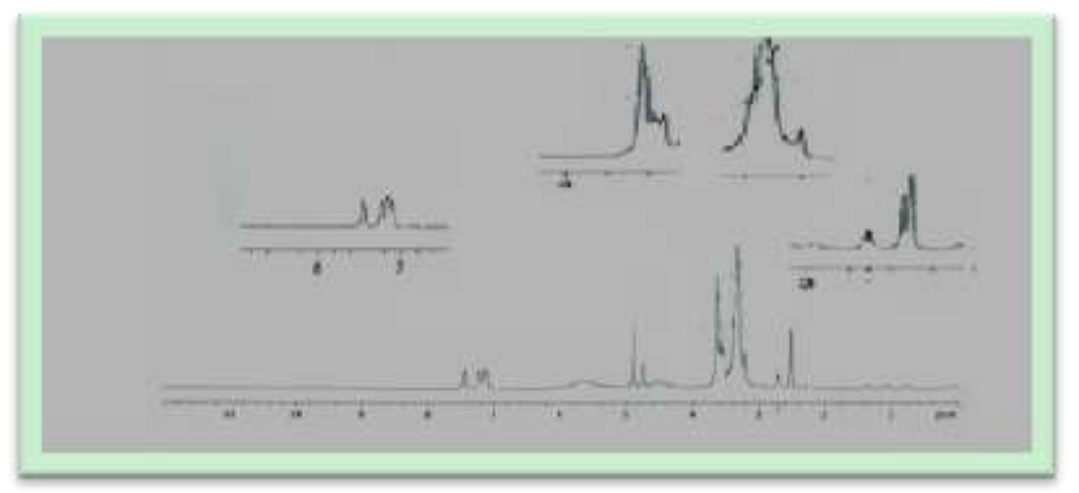

Figure 7. ${ }^{1} \mathrm{H}-\mathrm{NMR}$ spectra (300 MHz, in DMSO) for compounds (C)

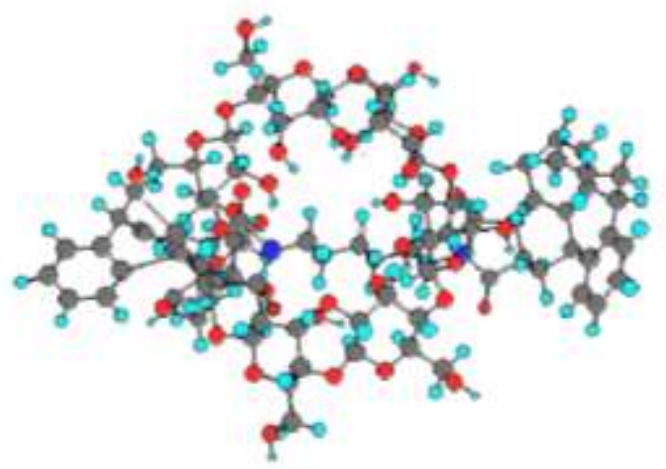

Figure 8 . The 3D structure of the inclusion complex (A)

\section{Conclusion}

In this work new [2] rotaxanes (A),(B) and (C) has been formed respectively with host-guest ratio 1:1. Threading method was used in preparation of these compounds. Thus, haxamethylenediamine as thread, cyclodextrins as macrocycle (host molecule) and 9,10-dihydro-9,10-ethanoanthracene-11,12-dicarboxlic anhydride as bulky groups. Elemental analysis, FT-IR, ${ }^{1}$ HNMR and Fast atom bombardment were applied to confirm the chemical structures of these inclusion complexes. The complexes indicating that the main driving forces of the complexation were hydrophobic- hydrophilic interactions and hydrogen bonds.

\section{Acknowledgment}

The author is grateful to her father Mr. Mohamed Qelay for his encouragement and continuous guidance and her family for their guidance and encouragement,

\section{References}

Balzani, A., Credi, A., Ragmo, F. M., \& Stoddart, J. F. (2000). Artificial molecular machines. J. Angew Chem. Int. Ed., 39, 3349-3391. http://dx.doi.org/10.1002/1521-3773(20001002)39:19<3348::AID-ANIE3348>3.0.CO;2-X

Baumes, J. M., Gassensmith, J. J, Giblin, J., Lee, J. J., White, A. G., Culligan, W. J., Leevy, W. M., Kuno, M., \& Smith, B. D. (2010). Storable thermally activated, near- infrared chemiluminescent dyes and dye- stained microparticles for optical imagine (2010). J. Nat. Chem., 2, 1025- 1030. http://dx.doi.org/10.1038/nchem.871

Breault, G. A.; Hunter, C. A.; Mayers, P. C. (1999). Tetrahedron, 55, 5265. http://dx.doi.org/10.1016/S0040-4020(99)00282-3

Browne, W. R., \& Feringa, W. R. (2006). Making molecular machine work. J. Nat. Nanotechnol, 1, 25-35. http://dx.doi.org/10.1038/nnano.2006.45

Brown, A., \& Beer, P. D. (2012). Prophyrin- functionalized rotaxanes for anion recognition. J. Dalton Trans., 41, 118-129. http://dx.doi.org/10.1039/C1DT11372K

Dardeer, H. M. (2014). Importance of cyclodextrins into inclusion complexes. International Journal of Advanced 
Research, 24, 414-428.

Evans, N. H., Serpell, G. J., \& Beer, P. D. (2011). Aredox- active [3] rotaxane capable of binding and electrochemically sensing chloride and sulphate anions. J. Chem. Commun, 47, 8775-8777. http://dx.doi.org/10.1039/c1cc13247d

Frisch, H. L., \& Wasserman, E. (1961). J. Am. Chem. Soc., 83, 3789. http://dx.doi.org/10.1021/ja01479a015

Gallina, M. E., Bytekin, B., Schalley, C., \& Ceroni, P. (2012). Light- Harvesting in multichromophoric Rotaxane. J. Chem. Eur., 18, 1528-1535. http://dx.doi.org/10.1002/chem.201102981

Gibson, H. W., Bheda, M. C., \& Engen, P. T. (1994). Prog. Polym. Sci., 19, 843-945. http://dx.doi.org/10.1016/0079-6700(94)90034-5

Gibson, H. W., \& Semlyen, J. A. (1996). Rotaxanes in Large Ring Molecules, Ed., John Wiley and Sons: New York, (6), 191-262.

Isnin, R., \& Kaifer, A. E. (1991). J. Am. Chem. Soc., 113, 8188-8190. http://dx.doi.org/10.1021/ja00021a067

Isnin, R., \& Kaifer, A. E. (1993). Pure Appl. Chem., 65, 495-498. http://dx.doi.org/10.1351/pac199365030495

Kay, E. R., Leigh, D. A., \& Zerhetto, F. (2007). Synthetic molecular motors and mechanical machines. J. Angew. Chem. Int. Ed., 46, 72-191. http://dx.doi.org/10.1002/anie.200504313

Kinbara, K., \& Aida, T. (2006). Toward intelligent molecular machines: Direct motions of biological and artificial molecules and assemblies. J. Chem. Rev., 105, 1377-1400. http://dx.doi.org/10.1021/cr030071r

Li, J. J., Zhao, F., \& Li, J. (2011). J. Appl. Microbiol. Biotechnol., 90, 427. http://dx.doi.org/10.1007/s00253-010-3037-x

Manka, J. S, \& Lawrence, D. S. (1990). J. Am Chem. Soc., 112, 2440-2442. http://dx.doi.org/10.1021/ja00162a066

Murakami, H., Kawabuchi, A., Kotoo, K., Kunitake, M., \& Nakashima, N. (1997). J. Am. Chem. Soc., 119(32), 7605-7606. http://dx.doi.org/10.1021/ja971438a

Niu, Z., Slebodnick, C., \& Gibson, H. W. (2011). J. Org. Lett., 13, 4616. http://dx.doi.org/10.1021/ol201837x

Sauvage, J. P., Dietrich-Buchecker, C., Eds. Molecular, Catenanes, Rotaxanes and Knots. (1999). A Journey through the World of MolecularTopology; Wiley VCH: Weinheim.

Schuster, D. I., Li, K., \& Guldi, D. M. (2006). Porphyrine fullerene photosynththetic model systems with rotaxane and catene and catenane architectures. J. CR. Chim., 9, 892-908. http://dx.doi.org/10.1016/j.crci.2005.11.013

Steinbrunn, M. B., \& Wenz, G. (1996). Angew Chem. Int. Ed. Engl., 35, 2139-2141. http://dx.doi.org/10.1002/anie.199621391

Thordarson, P., Bijsterveld, E. J. A., Rowan, A. E., \& Nolte, R. J. M. (2003). Epoxidation of polybutadiene by atopologically linked catalyst. J. Nature, 424, 915-918. http://dx.doi.org/10.1038/nature01925

Walba, D. M. (1985). Tetrahedron, 41, 3161. http://dx.doi.org/10.1016/S0040-4020(01)96671-2

Wange, J. Y., Han, J. M., Yan, J., Ma, Y. G., \& Pei, J. (2009). Amechanically Interlocked [3] Rotaxane as a light- Harvesting Antenna: Syntheys characterization and Intramolecular Energy. J. Transfer. Chem.Eur., 15, 3585-3594. http://dx.doi.org/10.1002/chem.200802228

Wang, X. Y., Bao, X. F., Farland-Mancini, M. Mc., \& Smithrud, D. B. (2007). Investigation of intracellular delivery of fluoresceinated peptides by host [2] rotaxane. J. Am. Chem. Soc., 129, 7284-7293. http://dx.doi.org/10.1021/ja067928x

Wenz, G. A. (1994). Chem., Int. Ed. Engl., 33, 803-822. http://dx.doi.org/10.1002/anie.199408031

Xi, G., Jian, H., Fengming, Q., Yang, Y., Zheng, H., Ruihua, L., \& Lizhen. (2011). Inclusion complexation with $\beta$-cyclodextrin: preparation, characterization and molecular modeling. J. Spectrochimica Acta, part A, 1-33.

\section{Copyrights}

Copyright for this article is retained by the author(s), with first publication rights granted to the journal.

This is an open-access article distributed under the terms and conditions of the Creative Commons Attribution license (http://creativecommons.org/licenses/by/3.0/). 